Journal of Advanced Research in Fluid Mechanics and Thermal Sciences

Journal homepage: www.akademiabaru.com/arfmts.html ISSN: 2289-7879

\title{
Preparation of Microcrystalline Cellulose from Oil Palm Empty Fruit Bunch Fibre Using Steam-Assisted Acid Hydrolysis
}

\author{
Fatiha Ismail ${ }^{1,}{ }^{*}$, Nur Eliyanti Ali Othman ${ }^{1}$, Noorshamsiana Abdul Wahab ${ }^{1}$, Fazliana Abdul Hamid ${ }^{1}$, \\ Astimar Abdul Aziz ${ }^{1}$ \\ 1 Biomass Technology Unit, Engineering \& Processing Research Division, Malaysian Palm Oil Board, 6, Persiaran Institusi, Bandar Baru Bangi, \\ 43000 Kajang, Selangor, Malaysia
}

\section{ARTICLE INFO}

\section{Article history:}

Received 16 December 2020 Received in revised form 15 February 2021

Accepted 18 February 2021

Available online 14 March 2021

\section{Keywords:}

Empty fruit bunch fibre; microcrystalline cellulose; acid hydrolysis; isolation; steam treatment

\section{ABSTRACT}

\begin{abstract}
The isolation of microcrystalline cellulose (MCC) from empty fruit bunch fibre (EFBfibre) using acid hydrolysis through steam treatment (autoclave) followed by ultrasonication has been successfully established. The important parameter studied was the concentration of sulphuric acid (5\%,15\% and $25 \%)$ at variable fixed reaction time and temperature. The resulting MCC was characterized using FTIR, TGA, XRD and SEM. FTIR transmission at $1163 \mathrm{~cm}^{-1}$ confirmed that the structure of cellulose was retained after undergoing acid hydrolysis. Thermal stability of MCC increased after being treated with $\mathrm{H}_{2} \mathrm{SO}_{4}$, which was determined using TG analysis. The morphological features were identified using Scanning Electron microscope (SEM), which showed the diameters of MCC to be in the range of 10 to $200 \mu \mathrm{m}$. The structural property of MCC was studied using X-ray diffraction (XRD) and the results showed that the MCC produced has crystallinity index of $72 \%$. The results revealed that the parameters used tend to influence the physicochemical properties of MCC produced. Therefore, the MCC isolated from EFB fibres will be used as precursor for future EFB derived nanocellulose as well as a promising subject in nanocomposite research.
\end{abstract}

\section{Introduction}

Malaysia has a plethora of biomass mainly from the oil palm industry [17]. Oil palm empty fruit bunches (OPEFB) is a major agricultural biomass by-product in Malaysia with each one tonne of crude palm oil resulting, approximately 1.1 tonne of waste residues [18]. OPEFB has been classified as lignocellulosic residue that typically contains $50 \%$ cellulose, $25 \%$ hemicellulose and $20 \%$ lignin as well as extractives in their cell walls. Cellulose is the most abundant sustainable natural biopolymer on earth and is found in a wide variety of living organisms, including plants, animals and some bacteria [21]. It is the key structural component of the plant and regains its value as a sustainable chemical resource for the replacement of petroleum-based materials $[2,23]$. Cellulose production is estimated to be over $7.5 \times 1010$ tonnes per year [12]. For economic feasibility, the cellulose extraction should be integrated with other chemicals extraction, such as the hemicellulose (xylan) and the lignin.

\footnotetext{
${ }^{*}$ Corresponding author.

E-mail address: fatihaismail@gmail.com
}

https://doi.org/10.37934/arfmts.81.1.8898 
Cellulose has natural fiber mechanical properties. It is arranged in microfibrils surrounded by two other main components: hemicellulose and lignin. Cellulose microfibrils are available in cellulose nanofibers with a diameter of 5-50 $\mathrm{nm}$ and a length of several millimeters.

Microcrystalline cellulose (MCC) is a white, fine, odorless, crystalline powder and biodegradable substance. It can be separated from pure cellulose by acidic hydrolysis [11,30]. The typical range of MCC crystallinity values recorded earlier was $55 \%$ to $80 \%$ as determined by XRD [6]. MCC was used as suspension stabilizer and water retainer in cosmetics, food and direct regulator for the production of tablets and soluble medicine $[6,7,13]$.

MCC is a material derived from purified and partially depolymerised cellulose that occurs naturally. It is prepared conventionally by the treatment of alpha-cellulose with excess mineral acids. The microfibrils that make up the alpha-cellulose are composed of paracrystalline and crystalline phases at nanometer scale. The paracrystalline field is an amorphous mass of cellulose strings, while the crystalline areas are composed of dense micro-crystal bundles in a compact linear structure. The crystalline regions are considered as cellulose crystalline regions and are formed by cellulose chains owing to van der Waals interactions and hydrogen bonding. The diameter of such crystals is in the same size as the diameter of the microfibrils of cellulose [19]. The amorphous phase is readily hydrolyzed when exposed to acid hydrolysis. This results in shorter and more crystalline parts, for example, MCC. As a result, the degree of polymerization of the cellulose chain is decreased with virtually no weight loss.

Numerous methods for extracting MCC from natural fiber have been studied. Haafiz et al., [11] obtained MCC from oil palm empty fruit bunch pulp, using an acid hydrolysis reaction of $2.5 \mathrm{~N}$ hydrochloric acid. In addition, Xiang et al., [22] isolated MCC from oil palm empty fruit bunch, by bleaching and alkali treatment with sodium chlorite and sodium hydroxide respectively, followed by acid hydrolysis with sulphuric acid. Kalita et al., [15] extracted MCC from feed grass using 4\% sodium hydroxide, followed by bleaching using a 1:1 mixture of sodium hypochlorite and hydrogen peroxide for pre-treatment processes. In addition, Merci et al., [25] researched the isolation of MCC from soya bean hulls by utilizing sodium hydroxide and sulphuric acid assisted by reactive extrusion. Commercial MCC of different properties were produced through extraction from wood and cotton using dilute mineral acids [6].

Steam-assisted pre-treatment is the most widely used process for pre-treatment of lignocellulose biomass [5,32]. In this process, the chipped biomass was treated with high-pressure saturated steam for a few seconds to several minutes, whereby there was an unexpected decrease in pressure. Steam explosion is a result of mechanical forces and chemical effects leading to hydrolysis (autohydrolysis) of acetyl hemicellulose groups. Compared with other pre-treatment techniques, steam explosions have many attractive features. These include the potential for significant improvement in enzymatic hydrolysis, lower environmental impact, lower capital expenditure, increased ability for energy production, lower chemicals and conditions for hazardous processes, and high sugar recovery [1].

MCC was obtained through the injection of the cellulose source material into a pressurized reactor by subjecting the cellulose material to a steam explosion under controlled conditions. Some researchers have suggested that steam explosion causes components of lignocellulosic material to be broken down by steam heating and shaving forces due to increased moisture and hydrolysis of glycosidic bonds formed by organic acid during the cycle [34].

Physicochemical methods also enhanced current chemical processes by mitigating reaction time and increasing process efficiency. Physical parameters, such as pressure and temperature, have been applied to the existing chemical pre-treatment in order to enhance lignin removal and increase their performance [9]. Previous studies showed ultrasonic treatment was able significant to enhance the extractability of the main components, such as hemicelluloses, cellulose and lignin in lignocellulosic 
biomass pre-treatment. Ultrasound enhances cleavage bonds within lignin as well as the bonds between lignin and hemicellulose. Cleavage reactions have been intensified by ultrasound-produced radicals and the shearing forces of ultrasonic mixing have increased the deterioration of polymers [4].

This study focused on characterizing the physicochemical properties of MCC obtained from OPEFB using autoclave technique. To date, there is limit information and research that reported on the technique used to isolate MCC from OPEFB by acid hydrolysis with different concentrations. This article reports on the effect of autoclave on the physicochemical properties of MCC, which has the ability to be applied as green filler for bio-composite applications. The physicochemical properties of MCC were characterized using Fourier transform infrared (FTIR) spectroscopy to confirm the basic structure of cellulose in MFC, while thermal stability was carried out using thermogravimetric analysis (TGA) and the surface morphology of MFC were monitored using scanning electron microscopy (SEM). This article also describes, for the first time, the isolation of MCC from OPEFB by pressurized steam, with the ability to be used as a green filler for biocomposite applications.

\section{Materials and Methods}

\subsection{Materials}

EFB shredded fibres were collected from Palm Oil Mill Technology Centre (POMTEC) located in Labu, Negeri Sembilan, Malaysia. The EFB shredded fibres were then transported to MPOB headquarters, Selangor for further processing.

\subsection{Preparation of Holocellulose and Cellulose}

The EFB shredded fibres were initially dried in the oven before use. Dried EFB shredded fibres with an average of $0.25 \mathrm{~mm}$ in length were used as a source of cellulose. The dried fibres were first de-lignified according to ASTM, D 1104-56 to produce holocellulose. In this step, about 4.0g of the fibres were soaked in distilled water and the sample was treated with $2.0 \mathrm{ml} 100 \%$ acetic acid (CheMAR) and 5.0g 99\% sodium chlorite (R\&M, United Kingdom) at $70^{\circ} \mathrm{C}$ for 4 hrs to degrade the lignin. The mixture was then filtered and the solid residue, which is the holocellulose, were washed with distilled water.

The next step was to remove the hemicellulose fraction according to ASTM, D 1103-60. About $2.0 \mathrm{~g}$ holocellulose was treated with $50 \mathrm{ml}$ of $17.5 \%$ sodium hydroxide solution (99\% Merck, Germany). The insoluble $\alpha$-cellulose was filtered and washed with $8.3 \%$ sodium hydroxide. The cleaned $\alpha$-cellulose was used as starting material for preparation of microcrystalline cellulose. The detailed characteristic and morphology of $\alpha$-cellulose (lignin content, FT-IR, XRD and SEM) were described in previous paper [31].

\subsection{Preparation of Microcrystalline Cellulose}

The purified cellulose fibers were then subjected to acid hydrolysis at different sulphuric acid concentrations. $1.0 \mathrm{~g}$ cellulose EFB fiber was mixed into $200 \mathrm{ml} 5 \%, 10 \%$ and $15 \%$ sulphuric acid solution respectively. The MCC was produced by hydrolyzing the $\alpha$-cellulose with three different acid concentrations (5\%,10\% and 15\%) under pressurized steam for 1 hour in a pressurized reactor (autoclave). This mixture was then ultrasonicated at $50^{\circ} \mathrm{C}$ for 3 hours. After ultrasonication, the suspension was then washed with distilled water and filtered to separate the MCC. The detailed characteristic and morphology of MCC were characterized using FTIR, SEM, TG and XRD analysis. 


\subsection{Characterization of Physicochemical Properties}

\subsubsection{Fourier transformed infrared spectroscopy analysis}

Infra-red spectra of samples were recorded using a Perkin Elmer - FTIR Spectrum One Spectrometer and transmission in the range of $650-4000 \mathrm{~cm}^{-1}$ was measured.

\subsubsection{Thermogravimetric analysis}

Thermogravimetric analysis (TGA) was performed using Mettler Toledo model to analyse the thermal behaviour of OPEFB and MFC samples. The samples were heated from 30 to $600^{\circ} \mathrm{C}$ with a heating rate of $10^{\circ} \mathrm{C} \mathrm{min}^{-1}$ under nitrogen gas atmosphere.

\subsubsection{Scanning electron microscopy}

The microscopic characteristics of the samples were tested using a Hitachi S2700 scanning electron microscope (SEM). A portion of the dry sample was placed on the SEM sample lens and then mounted in a vacuum chamber to prevent obstruction and other particles contamination. The imprint on the electron was converted into a three-dimensional image. The power of magnification used for the samples was 1000x.

\subsubsection{X-Ray diffraction}

X-ray diffraction (XRD) was conducted to test the sample crystallinity. All cellulosic and MCC samples were pressed to form pellets, and recorded using Ni-filtered $\mathrm{Cu}$ Ka radiation ( $30 \mathrm{kV}$ and 30 $\mathrm{mA}$ ) on X'Pert X-ray diffractometer (SIEMENs XRD D5000). The diffraction intensities were measured at step size $0.04^{\circ} \mathrm{min}^{-1}$ between ${ }^{5}-69^{\circ}$ Bragg angles (2 range). According to Segal 's formula, the crystallinity index $\left(C_{r} I\right)$ was calculated using intensity measurement at $22.5^{\circ}$ and $18.5^{\circ}$ (amorphous background) [30].

$C_{r} I(\%)=\frac{I_{002}-I_{a m}}{I_{002}} \times 100 \%$

where

$C_{r} I=$ crystallinity index

$I_{002}=$ maximum intensity (in arbitrary units) of the diffraction from the 002 plane at $2 \theta=22.5^{\circ}$

and $I_{a m}=$ intensity of the background scatter measured at $2 \theta=18.5^{\circ}$

\section{Results and Discussions}

\subsection{FTIR Spectroscopy}

FTIR spectra and peak assignments of EFB cellulose and MCC samples are summarized in Figure 1(a) and Figure 1(b), respectively. The FTIR spectra from all samples displayed two main absorbance regions, which are functional group region (4000 to $1300 \mathrm{~cm}^{-1}$ ) and fingerprint region (1300 to 400 $\mathrm{cm}^{-1}$ ). In general, the spectra for commercialised MCC and MCC isolated were comparable. All spectra identified the spectral bands located at 3400 to $3340 \mathrm{~cm}^{-1}$ which represented the $\mathrm{O}-\mathrm{H}$ stretching of intermolecular hydrogen bonds. The first observed spectral band reflected the hydroxyl group which 
was related to the content of moisture. This was where the $\mathrm{OH}$ bonded to the cellulose, hemicellulose and lignin structure. Unfortunately, in all spectra the weak peaks at $1735 \mathrm{~cm}^{-1}$ were appeared, which representing the acetyl and ester groups in hemicellulose and aromatic lignin components [26]. This indicated that the chemical structure of the cellulosic fragment of MCC was not affected by the different acid concentrations used in acid hydrolysis. However, the treatment with acid hydrolysis has successfully broken the glycosidic bond between lignin and other carbohydrate fractions, leading to a disruption of the lignin structure in cellulose [33]. Hence it is possible to detect the presence of more crystalline order in the MCC samples at peak $2900 \mathrm{~cm}^{-1}$. Various studies have also found that the band at $1163 \mathrm{~cm}^{-1}$ corresponds to the C O C $\alpha-1,4$-glycosidic bond stretching $[11,16]$. In all spectra, the peak at $897 \mathrm{~cm}^{-1}$ represents the $\beta$-glycosidic connections of glucose rings in cellulose [20]. Overall, the FTIR spectra showed that MCCs have been successfully isolated from EFB and are similar to commercialised MCC spectra.

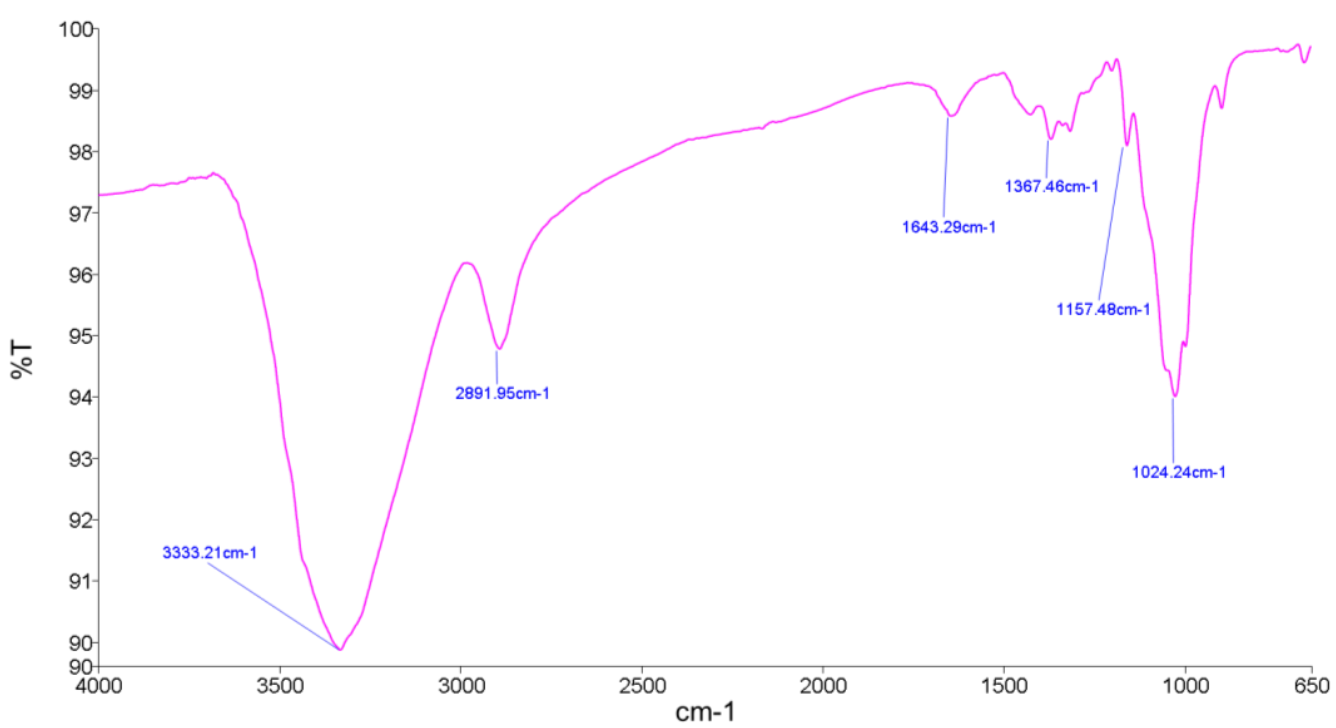

(a)

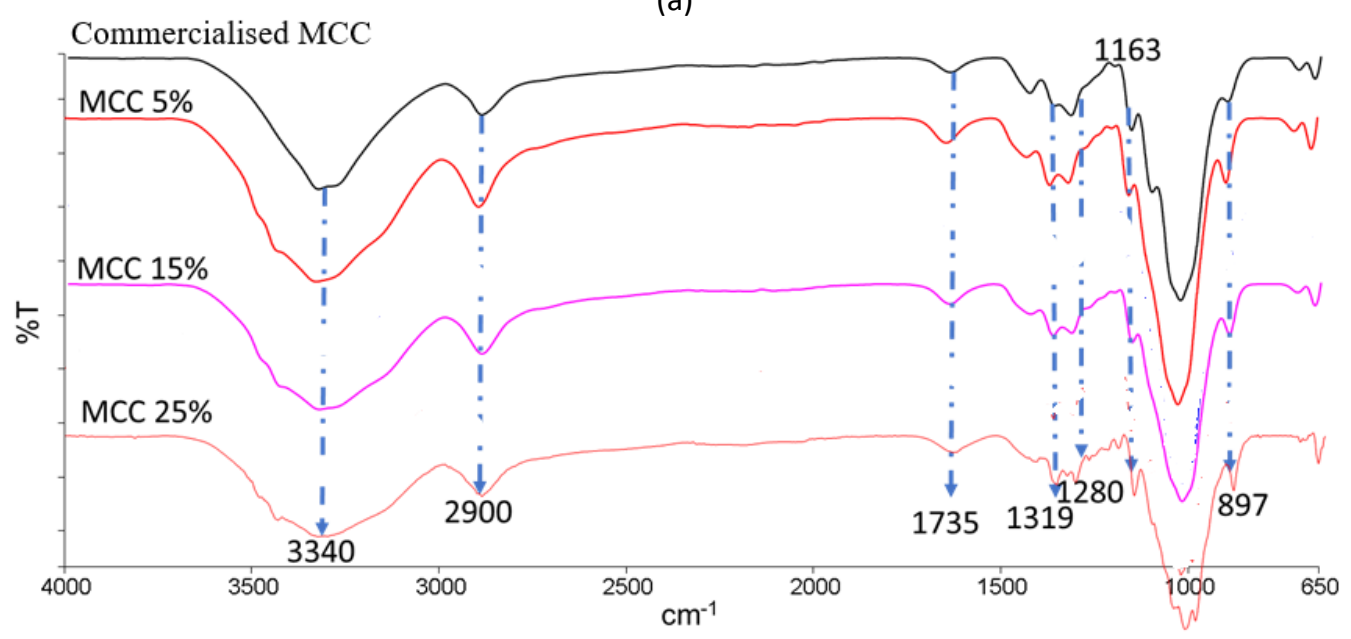

(b)

Fig. 1. (a) The FTIR spectra of EFB cellulose fibre, (b) The FTIR spectra of commercialised MCC and MCCs with different acid concentration used 


\subsection{Thermal Analysis of Cellulose and MCC}

After the chemical process, thermogravimetric analysis was used to determine the thermal stability of cellulose and MCCs as well as to elucidate the material changes. Understanding the thermal and degradation properties of MCC is critical in establishing its potential use in the manufacture of high-temperature biocomposites [10,14]. Figure 2 shows the TGA curves of all samples and the degradation temperatures before and after acid hydrolysis, which influenced the thermal stability of MCC as tabulated in Table 1 . It is noted that the region between 30 and $100^{\circ} \mathrm{C}$ corresponds to the removal of water and other volatile compounds within the cellulose [28]. Meanwhile, the second stage concerns the dehydration, decarboxylation, depolymerization and decomposition of cellulose glycosylic units accompanied by the formation of char residues in the range of $250-450^{\circ} \mathrm{C}$. OPEFB's onset temperature was the lowest when compared to other samples. Poletto et al., [27] stated that the degradation of hemicellulose occurs at temperatures between 180 and $350^{\circ} \mathrm{C}$. In the OPEFB DTA curve, hemicellulose was found to belong to the shoulder at $280^{\circ} \mathrm{C}$ because it degrades at lower temperatures compared to lignin and cellulose. MCC 1 showed the highest onset temperature $\left(250^{\circ} \mathrm{C}\right)$ among the MCCs produced, followed by MCC 2 and MCC 3 . This is due to the high crystallinity of cellulose in MCC 1 . The reorientation of the cellulose crystals promotes degradation at temperature onset (Mandal and Chakrabarty, 2011). The cellulose degradation occurs at a maximum temperature of $350^{\circ} \mathrm{C}\left(T_{\max }\right)$, according to Poletto et al., [27]. At this temperature the scissoring of glycosidic bonding occurs in cellulose. In conclusion, the TGA study revealed the purity of the MCC produced with thermal stability at $399.8^{\circ} \mathrm{C}$, which was verified and confirmed by comparing the findings with commercial MCC.

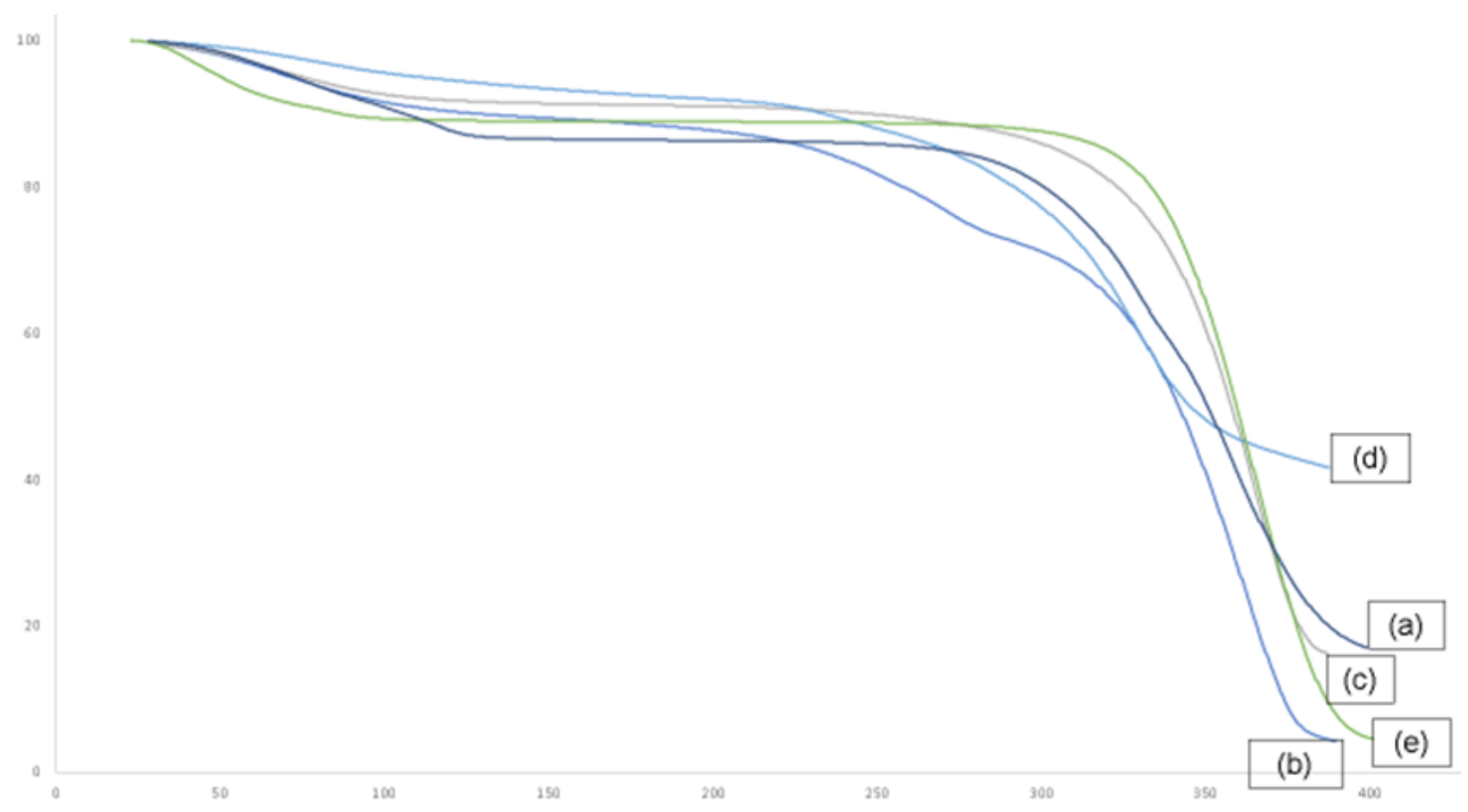

Fig. 2. Thermal decomposition of OPEFB Cellulose, MCCs and Commercialised MCC, (a) OPEFB Cellulose; (b) MCC 5\%; (c) MCC 15\%; (d)MCC 25\%; (e)Commercialised MCC 
Table 1

Thermal Analysis of Cellulose and MCC

\begin{tabular}{|c|c|c|}
\hline Samples & $\mathrm{T}_{50 \%}\left({ }^{\circ} \mathrm{C}\right)$ & $\mathrm{T}_{\text {max }}\left({ }^{\circ} \mathrm{C}\right)$ \\
\hline Cellulose & 318.9 & 357.9 \\
\hline MCC 1 & 313.5 & 359.4 \\
\hline MCC 2 & 328.6 & 364.0 \\
\hline MCC 3 & 281.6 & 328.5 \\
\hline Commercial MCC & 336.9 & 364.3 \\
\hline
\end{tabular}

\subsection{SEM Micrographs of Cellulose Before and After Acid Hydrolysis (MCC)}

The morphological structures of cellulose (before acid hydrolysis) and MCC (after acid hydrolysis) are seen in Figure 3. It was observed that the morphology of MCC was different after treatment. MCC's morphology showed that the diameter of MCC decreased along with the shortened length of the fibres when the concentration of sulphuric acid increased. The raw OPEFBs fibres prior to treatment composed of bundles that were bound together by lignin and hemicellulose. Their morphology has an irregular and rough surface of fibre bundles (Figure 3(a)). Further down in the process of turning the holocellulose into alpha-cellulose, uniform fibrils with smooth surface were formed, meanwhile, the treatment with 5 to $25 \%$ sulphuric acid caused the fibrils to become shorter and have rough surface as shown in Figure 3(c), Figure 3(d) and Figure 3(e). The structure of MCC varied from that of cellulose due to depolymerization of cellulose polymers to a shorter chained MCC [30]. The findings showed that acid treatment substantially reduced the width of the fibres. The average width of MCC decreased from $10 \mu \mathrm{m}$ to $3 \mu \mathrm{m}$ at $5 \%$ to $25 \% \mathrm{H}_{2} \mathrm{SO}_{4}$ concentration (Table 2). This finding is consistent with the study by Fahma et al., [8], in which it was found that the shape and diameter of the MCC formed depended greatly on the concentrations of acid and acid-fibre ratio. The MCC has a smooth external surface and uneven shape, which was likely due to the removal of silica, hemicellulose and lignin (Figure 3). This showed strong agreement with XRD tests, where the MCC had higher crystallinity index than EFB fibre cellulose.
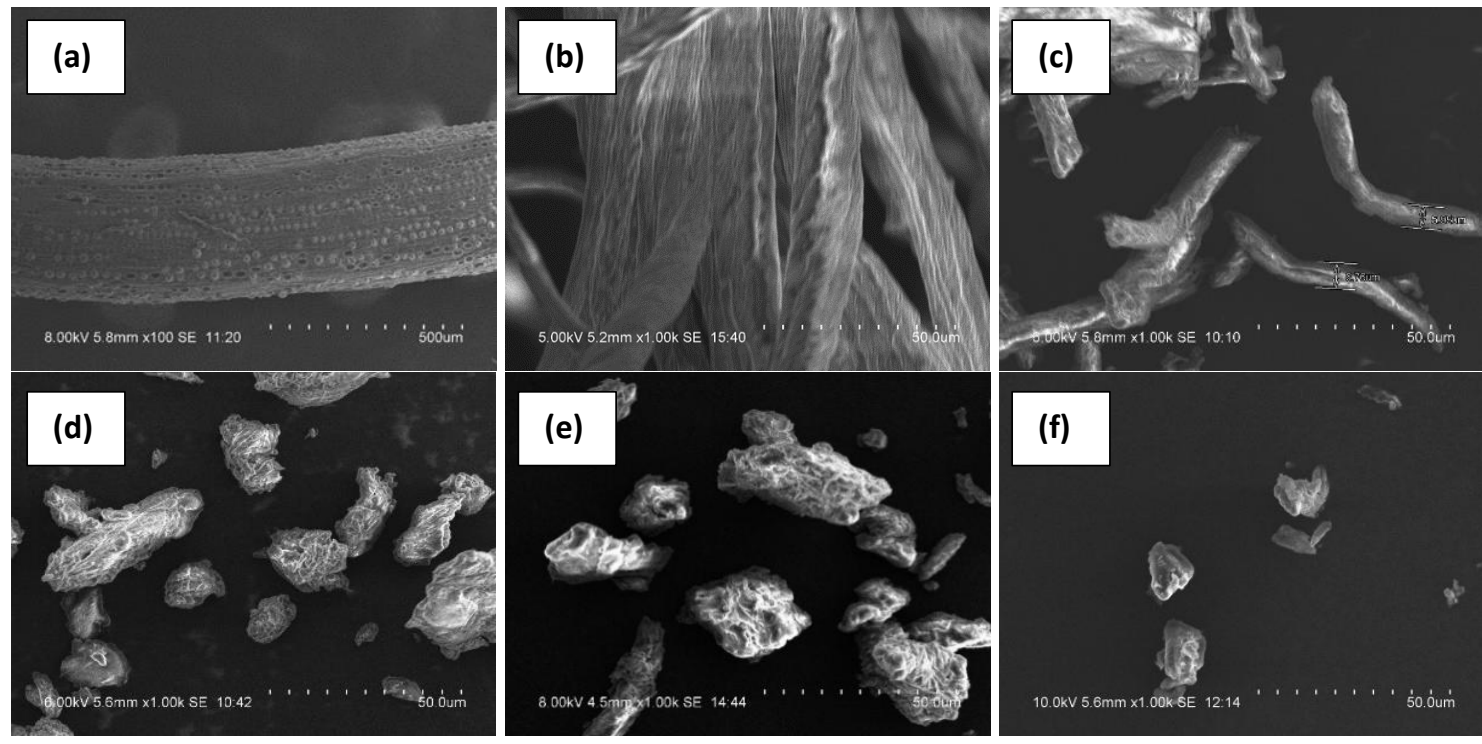

Fig. 3. The SEM micrograph of (a) EFB fibre, (b) EFB cellulose (c) MCC 5\%, (d) MCC 15\%, (e) MCC $25 \%$ and (f) commercialised MCC (1000x magnification) 
Table 2

Average diameter $(\mu \mathrm{m})$ of cellulose EFB fibre and MCC

\begin{tabular}{ll}
\hline Samples & Range diameter size $(\mu \mathrm{m})$ \\
\hline EFB fibre & 100 \\
Cellulose EFB fibre & 27.5 \\
MCC 5\% & 10 \\
MCC 15\% & 7 \\
MCC 25\% & 3 \\
Commercialised MCC & 3.5 \\
\hline
\end{tabular}

\subsection{XRD Analysis}

The degree of crystallinity of the products is usually measured using the X-ray diffraction method. The degree of crystallinity is the ratio of the crystalline areas to the amorphous areas of the cellulose. The X-ray diffraction patterns for cellulose OPEFB fibre, MCCs and commercialised MCC are shown in Figure 4 . The crystallinity value for MCCs increased after acid pre-treatment where the crystallinity value for MCC $25 \%$ was more crystalline and exhibited the highest percentage of $71 \%$ followed by MCC 15\% (57) and 5\% (54). This was attributed to its high decomposition temperature (TGA) and exhibited certain standard crystalline cellulose peaks in the region of $10-40^{\circ}$ [23]. Higher crystallinity is due to the more effective removal of nanocellulosic polysaccharides and the dissolution of amorphous regions. The crystallinity value was determined using the Segal equation. The crystallinity values for OPEFB fibre and commercialised MCC were $51 \%$ and $79 \%$, respectively (Table 3 ). As the overall extraction cycle began from cellulose OPEFB fibre to MCC isolation, the crystallinity index continued to increase due to the removal of certain hemicellulose and lignin in the amorphous regions [6]. The alignment of cellulose molecules is mostly located in this region. The results also confirm that hydrolysis takes place preferably in the amorphous region as acids dissolve the amorphous regions, while the crystalline regions are more stable towards chemical attacks. This reflected that the varied acid concentration treatment had no significant effect on the crystalline structure. As a result, the MCC $25 \%$ acid condition led to a more stable crystalline cellulose structure and greater strength of treated fibres. However, the interesting finding is that both samples displayed a single peak at $22.6^{\circ}$, reflecting the polymorphic structure of cellulose I. As a result, the concentration of acid hydrolysis did not influence the cellulose polymorph, which was close to the findings reported by Haafiz et al., [13] and Rosa et al., [28]. 

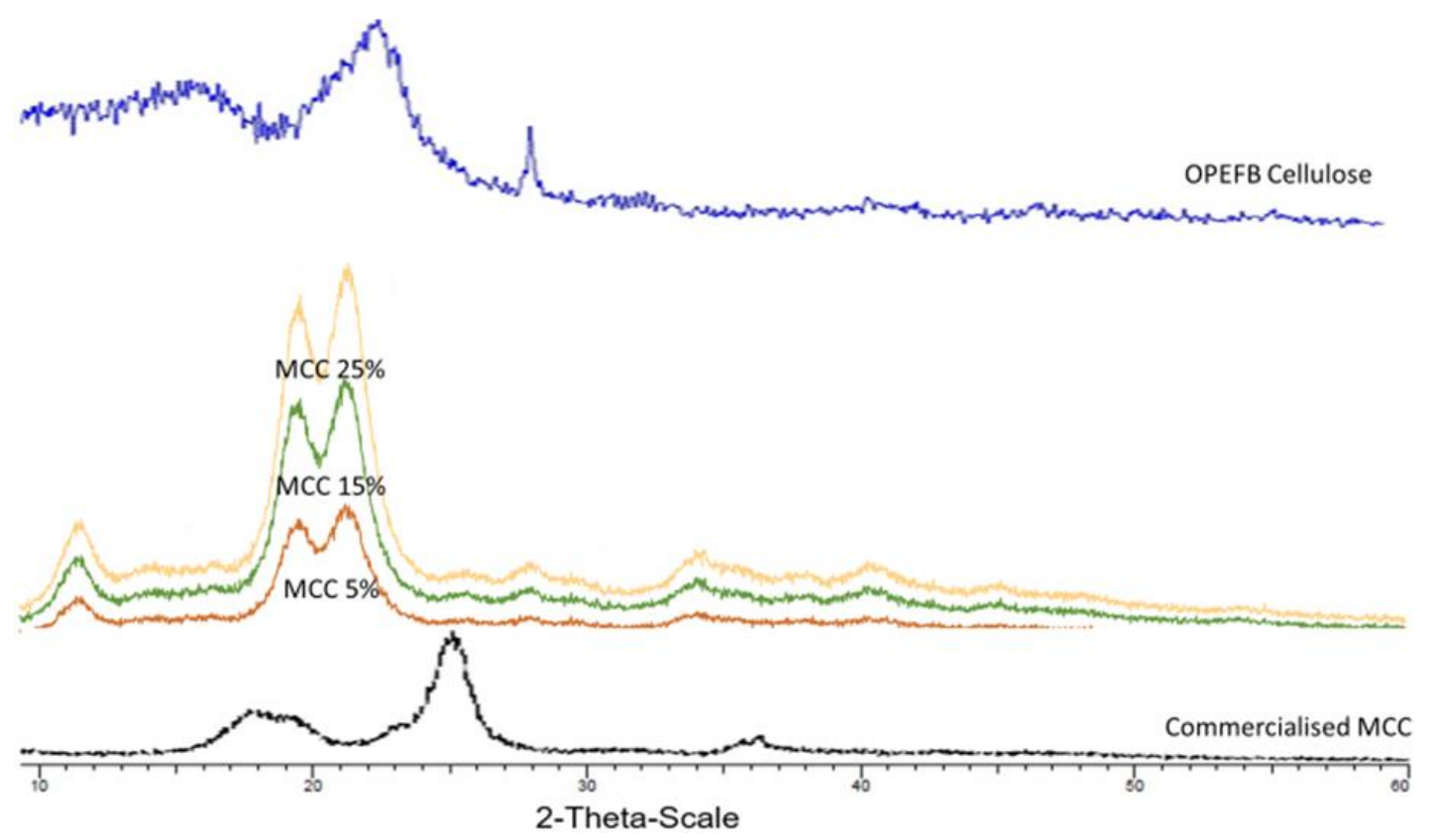

Fig. 4. Thermal decomposition of OPEFB Cellulose, MCCs and Commercialised MCC

Table 3

The crystallinity index of OPEFB Cellulose, MCCs and Commercialised MCC

\begin{tabular}{ll}
\hline Name & Crystallinity index \\
\hline OPEFB Cellulose & $51 \%$ \\
MCC 5\% & $54 \%$ \\
MCC 15\% & $57 \%$ \\
MCC 25\% & $71 \%$ \\
Commercialised MCC & $79 \%$ \\
\hline
\end{tabular}

\section{Conclusion}

Microcrystalline cellulose (MCC) was successfully isolated from oil palm empty fruit bunch fibres via steam-assisted acid hydrolysis with different acid concentration. Acid hydrolysis with sulphuric acid at low concentration as a pre-treatment method had produced MCC via the autoclave technique. Results show that acid concentration plays an effective role in the formation of different sizes of MCC. Analyses of the SEM images revealed that acid hydrolysis treatment does affect the morphological structure of the treated fibres (MCCs) as it exhibited a smaller particle dimension. The smallest diameter size produced was $8 \mu \mathrm{m}$ where MCC was treated with $25 \% \mathrm{H}_{2} \mathrm{SO}_{4}$. FT-IR analysis indicated that the acid hydrolysis did not influence the chemical structure of the treated fibre and MCCs, as well as it effectively remove lignin and hemicellulose from the raw cellulosic fibre. XRD analysis showed that the percentage of crystallinity of MCCs was notably influenced by acid concentration. However, the TGA analyses exposed that the extracted MCCs had a trustworthy maximal thermal durability. The MCC developed in this research will be utilized for extraction of nanocellulose and can further be used as nanocomposites for different applications.

\section{Acknowledgement}

The authors would like to thank the Director-General of MPOB for his permission to publish this article. 


\section{References}

[1] Avellar, Brecc K., and Wolfgang G. Glasser. "Steam-assisted biomass fractionation. I. Process considerations and economic evaluation." Biomass and Bioenergy 14, no. 3 (1998): 205-218. https://doi.org/10.1016/S09619534(97)10043-5

[2] Beck, Stephanie, Jean Bouchard, and Richard Berry. "Controlling the reflection wavelength of iridescent solid films of nanocrystalline cellulose." Biomacromolecules 12, no. 1 (2011): 167-172. https://doi.org/10.1021/bm1010905

[3] Bhattacharya, Deepanjan, Louis T. Germinario, and William T. Winter. "Isolation, preparation and characterization of cellulose microfibers obtained from bagasse." Carbohydrate Polymers 73, no. 3 (2008): 371-377. https://doi.org/10.1016/j.carbpol.2007.12.005

[4] Bussemaker, Madeleine J., and Dongke Zhang. "Effect of ultrasound on lignocellulosic biomass as a pretreatment for biorefinery and biofuel applications." Industrial \& Engineering Chemistry Research 52, no. 10 (2013): 3563-3580. https://doi.org/10.1021/ie3022785

[5] Chandra, R. P., R. Bura, W. E. Mabee, A. Berlin, X. Pan, and J. N. Saddler. "Substrate Pretreatment: The Key to Effective Enzymatic Hydrolysis of Lignocellulosics?." Advances in Biochemical Engineering/Biotechnology 108 (2007): 67-93. https://doi.org/10.1007/10 2007064

[6] Chuayjuljit, Saowaroj, Siriwan Su-uthai, and Sireerat Charuchinda. "Poly (vinyl chloride) film filled with microcrystalline cellulose prepared from cotton fabric waste: properties and biodegradability study." Waste Management \& Research 28, no. 2 (2010): 109-117. https://doi.org/10.1177/0734242X09339324

[7] El-Sakhawy, Mohamed, and Mohammad L. Hassan. "Physical and mechanical properties of microcrystalline cellulose prepared from agricultural residues." Carbohydrate Polymers 67, no. 1 (2007): 1-10. https://doi.org/10.1016/j.carbpol.2006.04.009

[8] Fahma, Farah, Shinichiro Iwamoto, Naruhito Hori, Tadahisa Iwata, and Akio Takemura. "Isolation, preparation, and characterization of nanofibers from oil palm empty-fruit-bunch (OPEFB)." Cellulose 17, no. 5 (2010): 977-985. https://doi.org/10.1007/s10570-010-9436-4

[9] Ismail, Fatiha, Noorshamsiana Abdul Wahab, Nur Eliyanti Ali Othman, and Astimar Abdul Aziz. "Physico-chemical Treatment of Oil Palm Biomass into Applicable Feedstock." Palm Oil Engineering Bulleting 129 (2018): 27-40.

[10] Ferrer, Ana, Carlos Salas, and Orlando J. Rojas. "Physical, thermal, chemical and rheological characterization of cellulosic microfibrils and microparticles produced from soybean hulls." Industrial Crops and Products 84 (2016): 337-343. https://doi.org/10.1016/i.indcrop.2016.02.014

[11] Haafiz, MK Mohamad, S. J. Eichhorn, Azman Hassan, and M. Jawaid. "Isolation and characterization of microcrystalline cellulose from oil palm biomass residue." Carbohydrate Polymers 93, no. 2 (2013): 628-634. https://doi.org/10.1016/i.carbpol.2013.01.035

[12] Habibi, Youssef, Lucian A. Lucia, and Orlando J. Rojas. "Cellulose nanocrystals: chemistry, self-assembly, and applications." Chemical Reviews 110, no. 6 (2010): 3479-3500. https://doi.org/10.1021/cr900339w

[13] Hussin, M. Hazwan, Nurul Aqilah Pohan, Zaharaddeen N. Garba, M. Jain Kassim, Afidah Abdul Rahim, Nicolas Brosse, Mehdi Yemloul, MR Nurul Fazita, and MK Mohamad Haafiz. "Physicochemical of microcrystalline cellulose from oil palm fronds as potential methylene blue adsorbents." International Journal of Biological Macromolecules 92 (2016): 11-19. https://doi.org/10.1016/i.ijbiomac.2016.06.094

[14] Jahan, M. Sarwar, Abrar Saeed, Zhibin He, and Yonghao Ni. "Jute as raw material for the preparation of microcrystalline cellulose." Cellulose 18, no. 2 (2011): 451-459. https://doi.org/10.1007/s10570-010-9481-z

[15] Kalita, Ranjan Dutta, Yutika Nath, Martins E. Ochubiojo, and Alak Kumar Buragohain. "Extraction and characterization of microcrystalline cellulose from fodder grass; Setaria glauca (L) P. Beauv, and its potential as a drug delivery vehicle for isoniazid, a first line antituberculosis drug." Colloids and Surfaces B: Biointerfaces 108 (2013): 85-89. https://doi.org/10.1016/i.colsurfb.2013.02.016

[16] Karim, Md, Zaira Zaman Chowdhury, Sharifah Bee Abd Hamid, and Md Ali. "Statistical optimization for acid hydrolysis of microcrystalline cellulose and its physiochemical characterization by using metal ion catalyst." Materials 7, no. 10 (2014): 6982-6999. https://doi.org/10.3390/ma7106982

[17] Kushairi, A., Meilina Ong-Abdullah, Balu Nambiappan, Elina Hishamuddin, M. N. I. Z. Bidin, Razmah Ghazali, Vijaya Subramaniam, Shamala Sundram, and Ghulam Kadir Ahmad Parveez. "Oil palm economic performance in Malaysia and R\&D progress in 2018." Journal of Oil Palm Research 31, no. 2 (2019): 165-194.

[18] Law, Kwei-Nam, Wan Rosli Wan Daud, and Arniza Ghazali. "Morphological and chemical nature of fiber strands of oil palm empty-fruit-bunch (OPEFB)." BioResources 2, no. 3 (2007): 351-362.

[19] Leppänen, Kirsi, Seppo Andersson, Mika Torkkeli, Matti Knaapila, Nina Kotelnikova, and Ritva Serimaa. "Structure of cellulose and microcrystalline cellulose from various wood species, cotton and flax studied by X-ray scattering." Cellulose 16, no. 6 (2009): 999-1015. https://doi.org/10.1007/s10570-009-9298-9 
[20] Le Troedec, Marianne, David Sedan, Claire Peyratout, Jean Pierre Bonnet, Agnès Smith, René Guinebretiere, Vincent Gloaguen, and Pierre Krausz. "Influence of various chemical treatments on the composition and structure of hemp fibres." Composites Part A: Applied Science and Manufacturing 39, no. 3 (2008): $514-522$. https://doi.org/10.1016/i.compositesa.2007.12.001

[21] de Souza Lima, M. Miriam, and Redouane Borsali. "Rodlike cellulose microcrystals: structure, properties, and applications." Macromolecular Rapid Communications 25, $\quad$ no. $7 \quad$ (2004): $771-787$. https://doi.org/10.1002/marc.200300268

[22] Xiang, Loo Yu, Mohd Afandi P. Mohammed, and Azhari Samsu Baharuddin. "Characterisation of microcrystalline cellulose from oil palm fibres for food applications." Carbohydrate Polymers 148 (2016): 11-20. https://doi.org/10.1016/i.carbpol.2016.04.055

[23] Ma, Hao, Bo Zhou, Hong-Sheng Li, Yi-Qun Li, and Shi-Yi Ou. "Green composite films composed of nanocrystalline cellulose and a cellulose matrix regenerated from functionalized ionic liquid solution." Carbohydrate Polymers 84, no. 1 (2011): 383-389. https://doi.org/10.1016/i.carbpol.2010.11.050

[24] Mandal, Arup, and Debabrata Chakrabarty. "Isolation of nanocellulose from waste sugarcane bagasse (SCB) and its characterization." Carbohydrate Polymers $86, \quad$ no. $3 \quad$ (2011): $1291-1299$. https://doi.org/10.1016/i.carbpol.2011.06.030

[25] Merci, Aline, Alexandre Urbano, Maria Victória E. Grossmann, Cesar A. Tischer, and Suzana Mali. "Properties of microcrystalline cellulose extracted from soybean hulls by reactive extrusion." Food Research International 73 (2015): 38-43. https://doi.org/10.1016/i.foodres.2015.03.020

[26] Nazir, M. S., B. A. Wahjoedi, A. W. Yussof, and M. A. Abdullah. "Green extraction and characterization of cellulose fibers from oil palm empty fruit bunch." In 2nd International Conference on Process Engineering and Advanced Materials (ICPEAM2012) under World Engineering, Science \& Technology Congress (ESTCON2012), Kuala Lumpur. 2012. https://doi.org/10.15376/biores.8.2.2161-2172

[27] Poletto, Matheus, Ademir J. Zattera, Maria MC Forte, and Ruth MC Santana. "Thermal decomposition of wood: Influence of wood components and cellulose crystallite size." Bioresource Technology 109 (2012): 148-153. https://doi.org/10.1016/i.biortech.2011.11.122

[28] Rosa, Simone ML, Noor Rehman, Maria Inez G. de Miranda, Sônia MB Nachtigall, and Clara ID Bica. "Chlorine-free extraction of cellulose from rice husk and whisker isolation." Carbohydrate Polymers 87, no. 2 (2012): 1131-1138. https://doi.org/10.1016/i.carbpol.2011.08.084

[29] Segal, L. G. J. M. A., J. Jr Creely, A. E. Martin Jr, and C. M. Conrad. "An empirical method for estimating the degree of crystallinity of native cellulose using the X-ray diffractometer." Textile Research Journal 29, no. 10 (1959): 786794. https://doi.org/10.1177/004051755902901003

[30] Soom, Rosnah Mat, Astimar Abd Aziz, Wan Hasamudin Wan Hassan, and Ab Gapor Md Top. "Solid-state characteristics of microcrystalline cellulose from oil palm empty fruit bunch fibre." Journal of Oil Palm Research 21, no. June (2009): 613-620.

[31] Soom, Rosnah Mat, Astimar Abdul Aziz, W. H. Wan Hassan, and Ab Gapor Md Top. "Conversion of lignocellulose from oil palm biomass into water-soluble cellulose ether." Journal of Oil Palm Research 24 (2012): 1412-1420.

[32] Singh, Joginder, Meenakshi Suhag, and Anil Dhaka. "Augmented digestion of lignocellulose by steam explosion, acid and alkaline pretreatment methods: a review." Carbohydrate Polymers 117 (2015): 624-631. https://doi.org/10.1016/i.carbpol.2014.10.012

[33] Trache, Djalal, M. Hazwan Hussin, Caryn Tan Hui Chuin, Sumiyyah Sabar, MR Nurul Fazita, Owolabi FA Taiwo, T. M. Hassan, and MK Mohamad Haafiz. "Microcrystalline cellulose: Isolation, characterization and bio-composites application-A review." International Journal of Biological Macromolecules 93 (2016): $789-804$. https://doi.org/10.1016/i.ijbiomac.2016.09.056

[34] Yu, Zhengdao, Bailiang Zhang, Fuqiang Yu, Guizhuan Xu, and Andong Song. "A real explosion: The requirement of steam explosion pretreatment." Bioresource Technology $121 \quad$ (2012): 335-341. https://doi.org/10.1016/i.biortech.2012.06.055 